\title{
Further investigation on microstructure refinement of internal crack initiation region in VHCF regime of high-strength steels
}

\author{
Yukun Chang \\ LNM, Institute of Mechanics, Chinese Academy of Sciences, Beijing 100190, China \\ School of Science, Harbin Institute of Technology, Shenzhen 518055, China \\ yukunchang@foxmail.com \\ Liang Zheng \\ School of Science, Harbin Institute of Technology, Shenzhen 518055, China \\ icon_lzheng@bit.edu.cn \\ Xiangnan Pan, Youshi Hong* \\ LNM, Institute of Mechanics, Chinese Academy of Sciences, Beijing 100190, China \\ School of Engineering Science, University of Chinese Academy of Sciences, Beijing 100049, China \\ panxiangnan@Inm.imech.ac.cn,hongys@imech.ac.cn
}

\begin{abstract}
The profile samples prepared by focused ion beam (FIB) in crack initiation region (CIR) and fish-eye (FiE) region of failed specimens subjected to rotary bending (RB) and ultrasonic axial (UL) fatigue testing with various stress ratios $(R)$ were observed by transmission electron microscopy (TEM) with selected area electron diffraction (SAD) detection for two high-strength steels. The grain size and the thickness of nanograin layer along the crack growth path in CIR underneath fine-granular-area (FGA) were measured for the cases of $R<0$, and a normalized quantity $d^{*}$ based on the detected SAD patterns was introduced to quantitatively demonstrate the variation of the grain size. The results showed that the nanograin size near the origin (an inclusion) of crack initiation is smaller than that away from the inclusion. Nevertheless, there was no evidence of grain refinement in CIR for the cases of $R>0$ and the FiE region outside CIR for either negative or positive stress ratio cases, which suggests that the formation of nanograin layer in the FGA region is due to the numerous cyclic pressing (NCP) process and the plastic deformation ahead of the crack tip may cause certain extent of microstructure deformation but is insufficient to form nanograin layer on crack surfaces.
\end{abstract}

KEYwORDS. Very-high-cycle fatigue; Nanograins; Microstructure refinement; Crack initiation; FGA; High-strength steels.

\section{OPEN ACCESS}

Citation: Chang Y.K., Pan X.N., Zheng L., Hong Y.S., Further investigation on microstructure refinement of internal crack initiation region in very-high-cycle fatigue regime of high strength steels, Frattura ed Integrità Strutturale, 49 (2019) 1-11.

Received: 08.04 .2019

Accepted: 23.04 .2019

Published: 01.07.2019

Copyright: (C) 2019 This is an open access article under the terms of the CC-BY 4.0, which permits unrestricted use, distribution, and reproduction in any medium, provided the original author and source are credited. 


\section{INTRODUCTION}

$\mathrm{F}$ atigue failure of engineering materials and structures bearing cyclic loading beyond $10^{7}$ cycles, i.e. very-high-cycle fatigue (VHCF), may still happen in practical industrial applications [1-4]. VHCF behavior has attracted the attention of researchers in recent decades due to increasingly realistic requirements and scientific interests [5-9]. At present, it has been known that the typical morphology of the internal crack initiation region (CIR) for VHCF of highstrength steels is a fish-eye (FiE) containing a relatively rough region of fine-granular area (FGA), and it surrounds an inclusion which is considered as the origin of the crack initiation [10-13]. In general, FGA is regarded as the characteristic region of the internal crack initiation of VHCF due to its stable value of related stress intensity factor range and the consumption of the majority of total fatigue life $[10,11,14]$.

As one of the most popular and challenging problems in VHCF, the formation mechanism of FGA has been investigated widely and deeply in last two decades [15-21]. Sakai et al. [18] examined the microstructure beneath the FGA by transmission electron microscopy (TEM). The TEM sample was prepared by focused ion beam (FIB) technique, and their results showed that the fine granular layer was observed in FGA region, whereas the fine polygonization was not observed in the location away from the FGA surface. Based on this observation, they proposed the model of "formation and debonding of fine granular layer" [22]. Similarly, an investigation by Grad et al. [15] reported that an average grain size of about $70 \mathrm{~nm}$ was observed in FGA for a high-strength steel and proposed an FGA formation mechanism called "local grain refinement at the crack tip". This model was extended very recently by Spriestersbach and Kerscher [23]. The most recent investigations by Chai et al. $[24,25]$ also believed that localized plastic deformation would promote the formation of FGA.

It should be noted that only the fully reversed cyclic loading was considered in all above-mentioned investigations, meaning the stress ratio of $R=-1$. In order to investigate the formation mechanism of FGA more deeply and comprehensively, Hong et al. [16] first performed fatigue tests under different stress ratios via rotary bending (RB) and ultrasonic axial (UL) loading for two high-strength steels, then the profile samples were prepared by FIB at the characteristic region of crack initiation of failed specimens, and subsequently the microstructure of the samples were examined by TEM. Their observations revealed the existence of the thin nanograin layer of FGA under negative stress ratios, whereas the morphology of FGA was diminishing or even extinguishing under positive stress ratios without the evidence of nanograin feature. Based on such experimental results, a new model named "numerous cyclic pressing (NCP)" was proposed to describe the formation processes of FGA. Subsequently, some results obtained by our group on structural steels [26] and titanium alloys [27,28] have confirmed the NCP model. Most Recently, numerical and experimental results reported by Ritz et al. [29] also validated the NCP model.

Despite the formation mechanism of FGA has been investigated widely by researchers, the effect of the plastic deformation ahead of the crack tip during crack initiation process on the microstructure refinement, and the more detailed characteristics of microstructure in CIR and FiE regions, are still not clear at the present time. Therefore, in this paper, further investigation was carried out on the microstructure features in the CIR and FiE regions for high-strength steels bearing fatigue loading up to very-high-cycle regime. Several profile samples prepared by FIB in CIR and FiE regions were examined by TEM with selected area electron diffraction (SAD) detection. The detailed observations indicate that the nanograin size near the origin of crack initiation is smaller than that away from the origin for the cases of $R<0$, and higher compressive stress and longer loading cycles promote the microstructure refinement. Nevertheless, there was no evident grain refinement in CIR for the cases of $R>0$ and the FiE region outside CIR for either negative or positive $R$ cases, suggesting that the formation of nanograins in the FGA region is due to the NCP process and the plastic deformation ahead of crack tip may cause certain extent of microstructure deformation but is insufficient to form nanograin layer on crack surfaces.

\section{TEST MATERIALS AND EXPERIMENTAL PROCEDURE}

\section{Test materials}

7 he test materials utilized in this research were two high-strength steels. For convenience, they were marked as material A and material B, respectively. The corresponding chemical compositions are listed in Tab. 1. Two heattreatment processes were performed: austenization at $845^{\circ} \mathrm{C}$ for $2 \mathrm{~h}$ in vacuum, oil-quenched then tempered for 2 $\mathrm{h}$ in vacuum at $180^{\circ} \mathrm{C}$ for the specimens of material $\mathrm{A}$, and austenization at $845^{\circ} \mathrm{C}$ for $1 \mathrm{~h}$ in vacuum, oil-quenched then tempered for $2 \mathrm{~h}$ in vacuum at $180{ }^{\circ} \mathrm{C}$ for the specimens of material B. After such heat-treatment processes, identical 
microstructure of tempered martensite was obtained. Results of monotonic quasi-static tensile and micro-hardness tests exhibited their high strength and hardness with the ultimate tensile strength of $1849 \mathrm{MPa}$ and the micro-hardness of 753 $\mathrm{Hv}\left(\mathrm{kgf} / \mathrm{mm}^{2}\right)$ for material $\mathrm{A}$, and the ultimate tensile strength of $1896 \mathrm{MPa}$ and the micro-hardness of $760 \mathrm{Hv}$ $\left(\mathrm{kgf} / \mathrm{mm}^{2}\right)$ for material B.

\begin{tabular}{cccccccc}
\hline Material & $\mathrm{C}$ & $\mathrm{Cr}$ & $\mathrm{Mn}$ & $\mathrm{Si}$ & $\mathrm{S}$ & $\mathrm{P}$ & $\mathrm{Fe}$ \\
$\mathrm{A}$ & 1.06 & 1.04 & 0.88 & 0.34 & 0.005 & 0.027 & Balance \\
$\mathrm{B}$ & 1.04 & 1.51 & 0.29 & 0.24 & 0.003 & 0.0058 & Balance \\
\hline
\end{tabular}

Table 1: Chemical compositions (wt. \%) of two materials.

\section{Experimental procedure}

Rotary bending and ultrasonic axial loading are commonly used in the VHCF tests of materials. In the previous research developed in our group, material $A$ was tested on a rotary bending machine with $R=-1$, and material $B$ was tested on an ultrasonic machine (equipped with a tensile facility to superimpose required mean stress) running at the resonant frequency of $20 \mathrm{kHz}$ with the stress ratios of $R=-1,-0.5,0.1$ and 0.3 . More detailed information concerning the fatigue tests was described in [16]. Then the morphology of the fracture surface was observed by scanning electron microscopy (SEM), and it was noticed that the failure of every specimen was due to internal cracking originated from an inclusion [16]. In addition, for the purpose of investigating the characteristics of microstructure for FGA and FiE on the fracture surface, several specimens under various loading conditions were cut by FIB to obtain the profile samples, and their relevant data were listed in Tab. 2. Subsequently these samples were carefully examined by TEM, especially near the fracture surfaces, and the microstructure details were detected by SAD with an aperture diameter of $200 \mathrm{~nm}$.

\begin{tabular}{ccccccc}
\hline Sample & $\begin{array}{c}\text { Loading } \\
\text { condition }\end{array}$ & $\sigma_{\mathrm{a}} / \mathrm{MPa}$ & $\sigma_{\max } / \mathrm{MPa}$ & $\sigma_{\min } / \mathrm{MPa}$ & $N_{\mathrm{f}} /$ cycles & $\begin{array}{c}\text { Sampling } \\
\text { location }\end{array}$ \\
A1 & $\mathrm{RB}, \mathrm{R}=-1$ & 775 & 775 & -775 & $2.40 \times 10^{7}$ & $\mathrm{CIR}$ \\
A2 & $\mathrm{RB}, \mathrm{R}=-1$ & 750 & 750 & -750 & $5.08 \times 10^{7}$ & $\mathrm{FiE}$ \\
B1 & $\mathrm{UL}, \mathrm{R}=-1$ & 989 & 989 & -989 & $1.11 \times 10^{8}$ & $\mathrm{CIR}$ \\
B2 & $\mathrm{UL}, \mathrm{R}=-0.5$ & 633 & 844 & -422 & $4.81 \times 10^{8}$ & $\mathrm{CIR}$ \\
B3 & $\mathrm{UL}, \mathrm{R}=0.1$ & 534 & 1187 & 119 & $1.84 \times 10^{7}$ & $\mathrm{CIR}$ \\
B4 & $\mathrm{UL}, \mathrm{R}=0.3$ & 430 & 1229 & 368 & $8.70 \times 10^{8}$ & $\mathrm{CIR}$ \\
B5 & $\mathrm{UL}, \mathrm{R}=0.3$ & 430 & 1229 & 368 & $8.70 \times 10^{8}$ & $\mathrm{FiE}$ \\
\hline
\end{tabular}

Table 2: Loading conditions and sampling locations of several failed specimens.

\section{RESULTS AND DISCUSSION}

\section{Microstructural features in CIR for negative stress ratio cases}

I t can be seen from Tab. 2 that A1, B1 and B2 samples were cut from CIR of the failed specimens bearing fatigue loading with negative stress ratios in VHCF regime. Fig. 1 illustrates the microstructural features of sample A1. It is seen from Fig. 1a that the crack initiated from a spherical inclusion then to form an FGA region. The small dashed yellow rectangle in Fig. 1a represents the sampling location in the FGA region, and Fig. 1b illustrates the bright field imaging (BFI) of sample A1. Figs. 1c and 1d show the SAD patterns at the locations just underneath the FGA surface with discontinuous diffraction rings of polycrystals, which suggests that there are several grains within the diffraction area of $200 \mathrm{~nm}$ in diameter. Figs. 1e and 1f are dark field images (DFI) of the left and right dashed green boxes marked in Fig. $1 \mathrm{~b}$, and the fine granular layer can be clearly observed in both figures.

Fig. 2 illustrates the microstructural features of sample B1. Similar to the above situation of sample A1, in the failed specimen associated with sample B1, the crack also originated from an inclusion to form an FGA region. BFI and DFI of the sample, displayed as a small dashed yellow rectangle in Fig. 2a, are presented in Figs. 2b and 2c, respectively. Both BFI 
and DFI showed that there are many fine grains near the fracture surface. SAD patterns of the left, middle and right dashed yellow circles marked in Fig. $2 \mathrm{~b}$ are illustrated in Figs. 2d-f. All of these three patterns are discontinuous diffraction circles, suggesting several grains existing at these different locations. Similar results were obtained for sample B2 (as shown in Fig. 3).
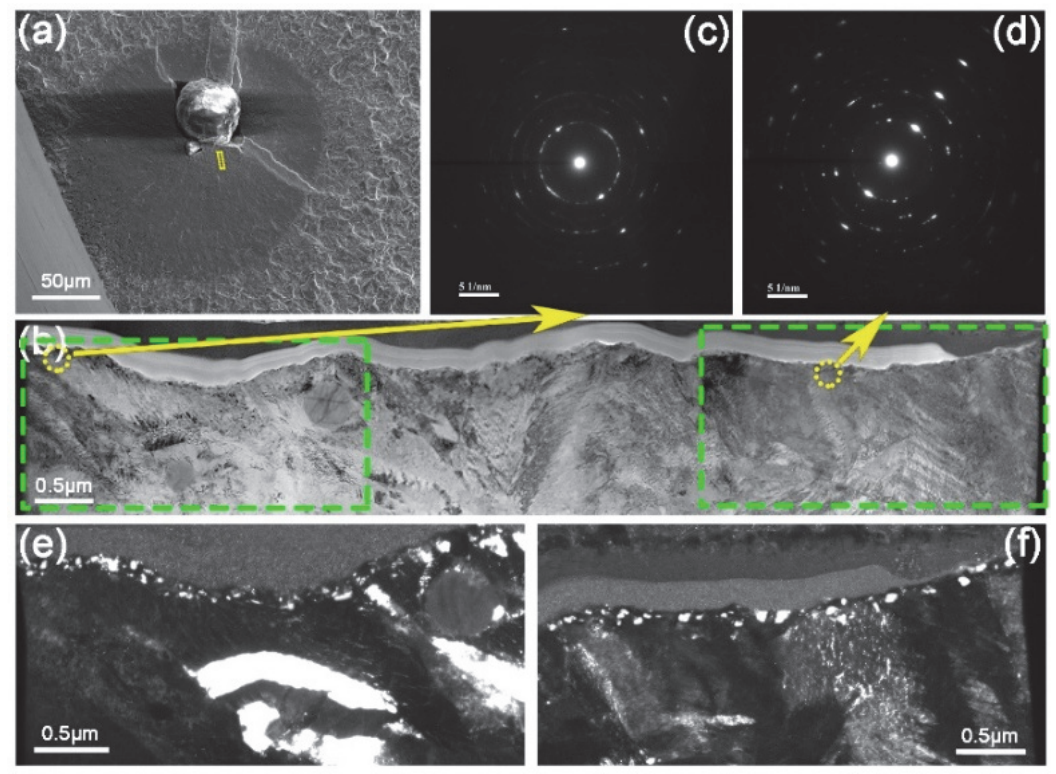

Figure 1: Microstructural features of sample A1 (RB, $R=-1, \sigma_{\mathrm{a}}=775 \mathrm{MPa}, N_{\mathrm{f}}=2.40 \times 10^{7}$ ), (a) SEM image of CIR showing the sampling location by a marked dashed yellow rectangle; (b) BFI; (c,d) SAD patterns of the left and right dashed yellow circles in (b); $(\mathrm{e}, \mathrm{f}) \mathrm{DFI}$ of the left and right dashed green boxes in (b).
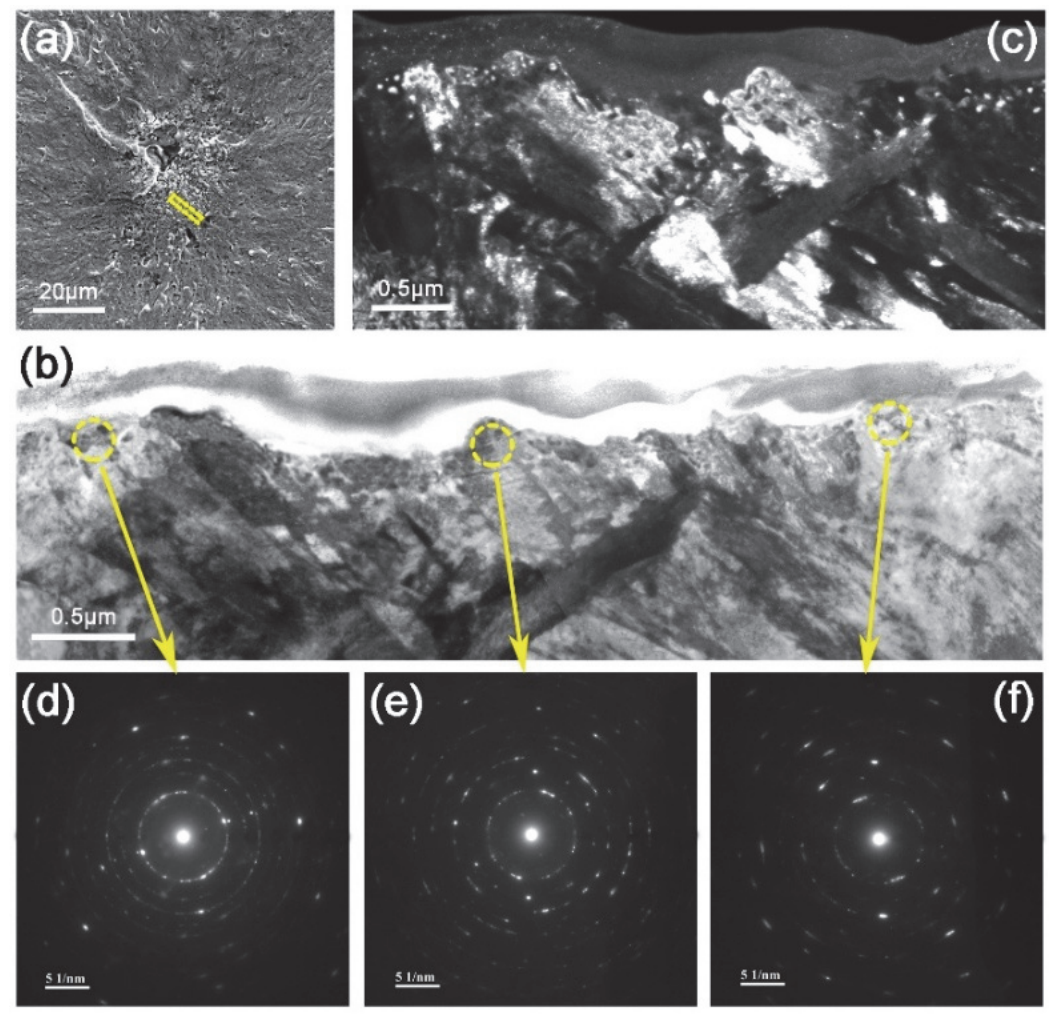

Figure 2: Microstructural features of sample B1 (UL, $R=-1, \sigma_{\mathrm{a}}=989 \mathrm{MPa}, N_{\mathrm{f}}=1.11 \times 10^{8}$ ), (a) Origin of crack initiation showing clear FGA feature; (b) BFI; (c) DFI; (d-f) SAD patterns of the left, middle and right dashed yellow circles in (b). 

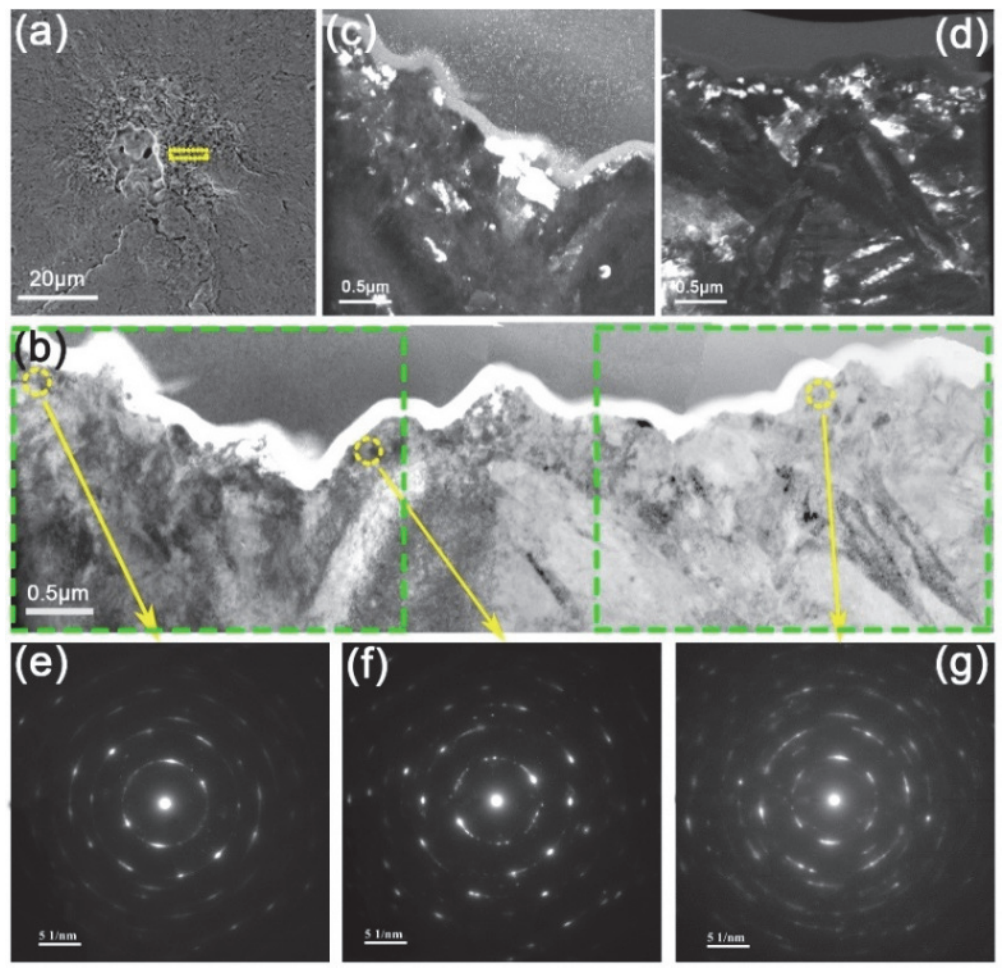

Figure 3: Microstructural features of sample B2 (UL, $R=-0.5, \sigma_{\mathrm{a}}=633 \mathrm{MPa}, N_{\mathrm{f}}=4.81 \times 10^{8}$ ), (a) SEM image showing crack origin; (b) BFI; (c,d) DFI of the left and right dashed green boxes in (b); (e-g) SAD patterns of the left, middle and right dashed yellow circles in (b).

The above experimental results indicate the existence of nanograins in CIR underneath FGA surface for the cases of $R=$ -1 and -0.5 under RB and UL loading conditions, confirming that the nature of FGA is a nanograin layer [16]. For the detail investigation of the relationship between the grain size and loading conditions, the distribution of grain size in CIR underneath FGA surface for samples A1, B1 and B2 was measured and the results are illustrated in Fig. 4. It is seen from Fig. 4 that the grain size ranges from $20 \mathrm{~nm}$ to $130 \mathrm{~nm}$, and the average equivalent diameters are $54 \mathrm{~nm}, 48 \mathrm{~nm}$ and $73 \mathrm{~nm}$ for A1, B1 and B2, respectively. Similarly, the distribution of thickness for these nanograin layers along the crack growth path was shown in Fig. 5, indicating that the average values of thickness are $315 \mathrm{~nm}, 435 \mathrm{~nm}$ and $386 \mathrm{~nm}$ for A1, B1 and B2, respectively. Note that the data in Figs. 4 and 5 are largely discrete, which suggests that the grain size and the thickness of nanograin layer are affected by cyclic loading condition and the microstructure of the material.

As an effective method for analyzing the microstructure of materials, SAD technique can be utilized to reveal the essential characteristics of the microstructure more objectively. According to the diffraction principle [30], SAD patterns will appear as a series of rings if it contains many grains with different orientations within the selected area, and with the increase of the number of grains, namely more fine grains, diffraction rings will become more continuous. Therefore, for the purpose of quantitatively describing the distribution of grain size under different loading conditions, a normalized quantity $d^{*}$ is introduced and expressed as:

$$
d^{*}=\frac{l}{l_{0}}
$$

where $l_{0}$ presents the perimeter of a completely continuous diffraction ring associated with a given crystal plane family, and $l$ presents total lengths of the ring measured in experiments.

For this purpose, a number of discontinuous diffraction rings associated with $\{110\}$ planes for samples A1, B1 and B2 were measured, and the results described by $d^{*}$ are illustrated in Fig. 6. The value of $d^{*}$ notably decreases along the crack growth path, implying that the size of nanograins gradually increases with the propagation of the crack, which may be due to gradually-reduced pressing actions. Moreover, the datum points of B1 are evidently higher than those of A1 and B2, suggesting that the greater compressive stress and the longer loading cycles may promote the grain refinement. 


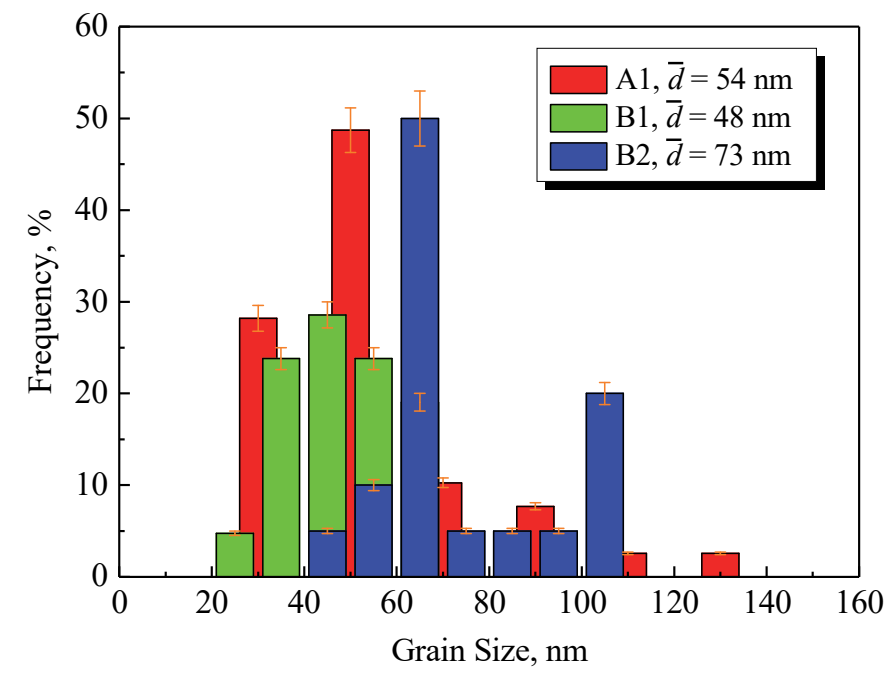

Figure 4: Distribution of grain size underneath FGA surface for samples A1, B1 and B2.

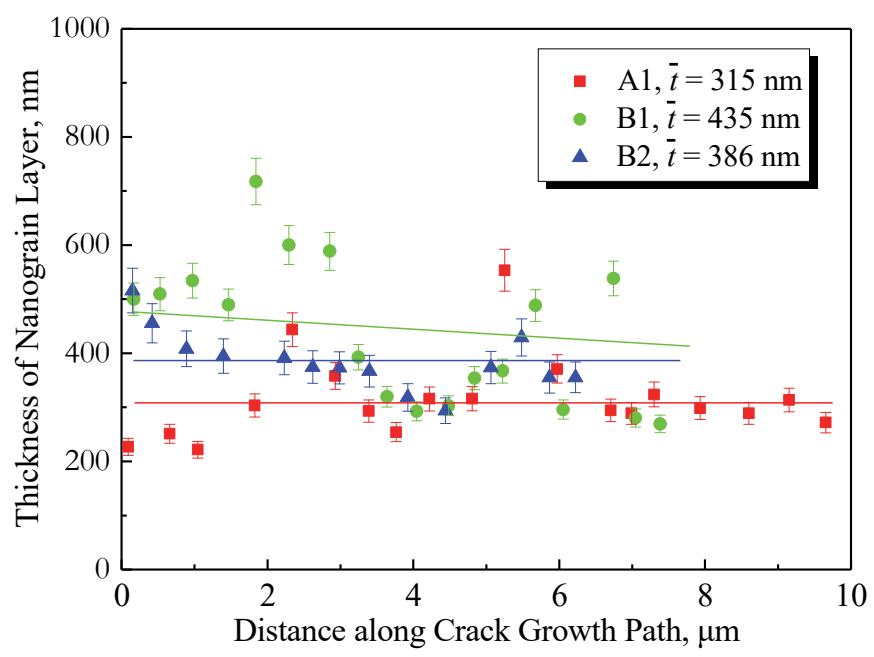

Figure 5: Thickness of nanograin layer along crack growth path underneath FGA surface for samples A1, B1 and B2.

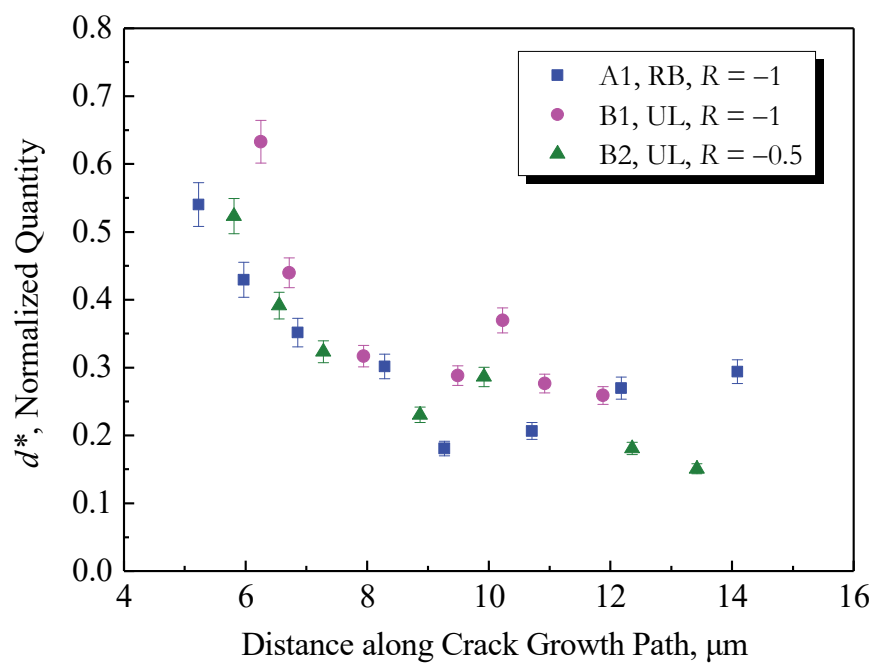

Figure 6: Distribution of normalized quantity $d^{*}$ versus crack growth path for samples A1, B1 and B2. 
Microstructural features in CIR for positive stress ratio cases

The above results indicate that the features of nanograins clearly prevailed underneath the fracture surface in the FGA region for the cases with negative stress ratios, whereas the microstructural features were not clear for the cases with positive stress ratios. It is well known that the plastic deformation occurs at crack tip. Based on the equation proposed by Murakami et al. [31]:

$$
K_{\max }=c \sigma_{\max }(\pi \sqrt{\text { area }})^{1 / 2}
$$

and the plastic zone size $\left(r_{\mathrm{p}}\right)$ at crack tip under plane strain condition [32]:

$$
r_{\mathrm{p}}=\frac{1}{6 \pi}\left(\frac{K_{\max }}{\sigma_{\mathrm{y}}}\right)^{2}
$$

the value of $K_{\max }$ increases with the raise of $\sigma_{\max }$ and crack size, causing the expansion of the plastic zone near the crack tip. In order to investigate the effect of the plastic deformation at the crack tip on the microstructure of high-strength steels, two profile samples cut in CIR (B3 and B4) with positive stress ratios and two samples cut in FiE (A2 and B5) were prepared. The results of the samples cut in CIR are presented in this section, and the results of samples cut in FiE will be presented in next section.

Fig. 7 illustrates the microstructural features of sample B3 $(R=0.1)$, and the sampling location is denoted by a small dashed yellow rectangle shown in Fig. 7a, from which a cluster of inclusions as the origin of crack initiation and the diminishing FGA feature can be clearly observed. Fig. 7b presents the whole BFI of sample B3, and the DFI of its local location (dashed green box) is illustrated in Fig. 7c, showing that any position on the profile is original martensite microstructure, meaning no sign of grain refinement. Fig. 7d shows the SAD pattern of slightly elongated diffraction spots, which is the result of localized plastic deformation. Fig. 7e shows the SAD pattern with typical isolated spots, which are the normal diffraction of a single crystal, i.e., the original coarse martensite microstructure. Similar observations of sample B4 $(R=0.3)$ are obtained as shown in Fig. 8 .
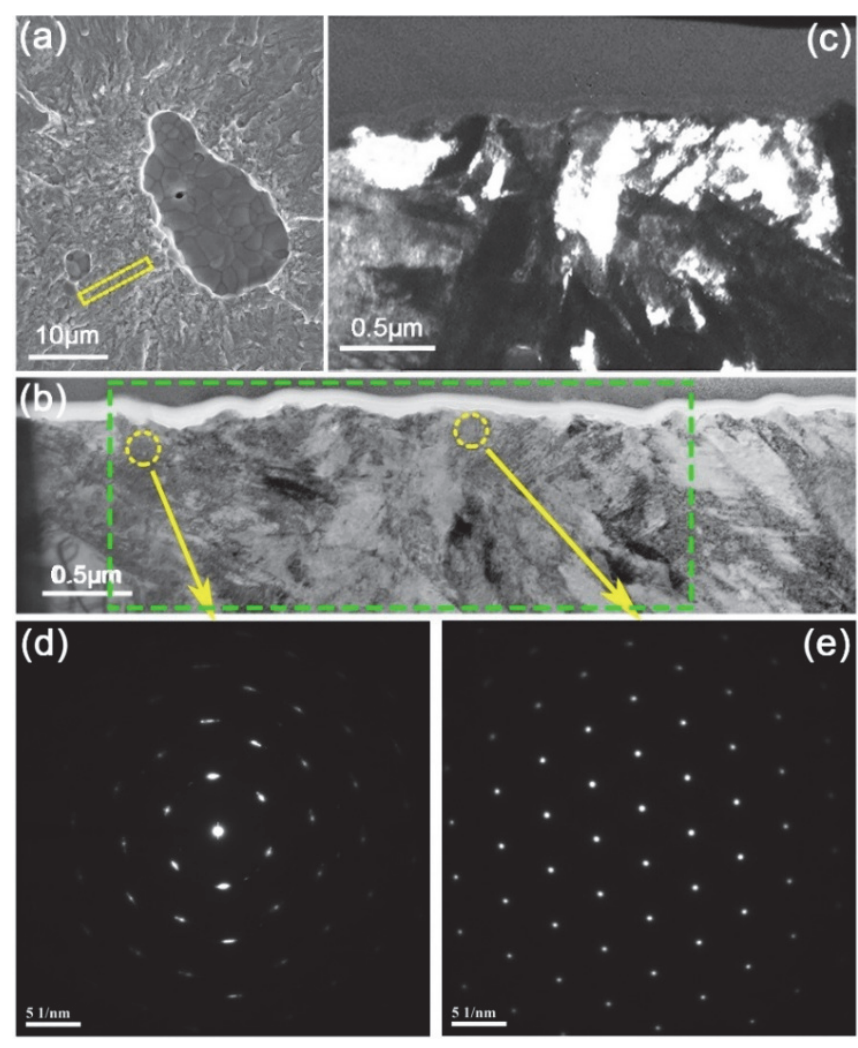

Figure 7: Microstructural features of sample B3 (UL, $R=0.1, \sigma_{\mathrm{a}}=534 \mathrm{MPa}, N_{\mathrm{f}}=1.84 \times 10^{7}$ ), (a) SEM image showing crack origin; (b) BFI; (c) DFI of the dashed green box in (b); (d,e) SAD patterns of the left and right dashed yellow circles in (b). 

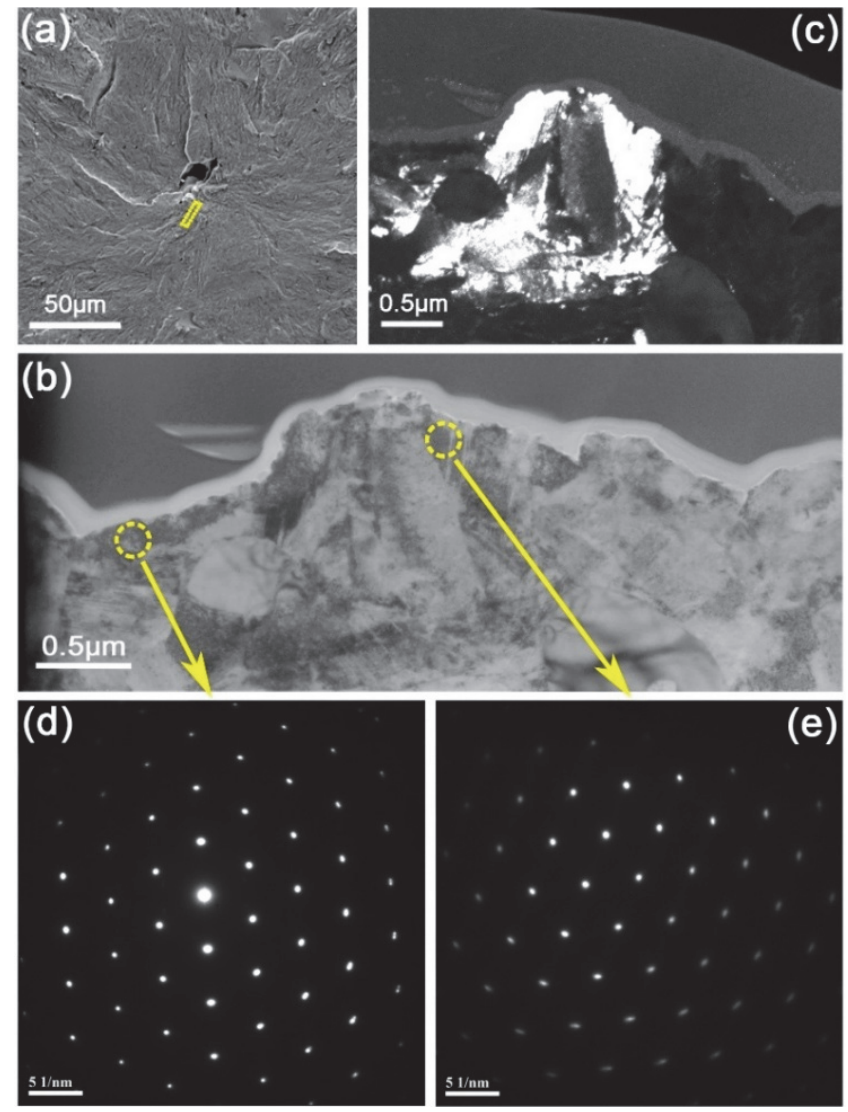

Figure 8: Microstructural features of sample B4 (UL, $R=0.3, \sigma_{\mathrm{a}}=989 \mathrm{MPa}, N_{\mathrm{f}}=8.70 \times 10^{8}$ ), (a) SEM image showing crack origin; (b) BFI; (c) DFI; (d,e) SAD patterns of the left and right dashed yellow circles in (b).

\section{Microstructural features in FiE}

Fish-eye is a typical morphology of VHCF for metallic materials, but the microstructural features in the FiE region were not very clear so far. For the purpose of further examination for the microstructure features in FiE, two profile samples (A2 and B5) were prepared by FIB cut from the FiE region of failed specimens in VHCF regime under $\mathrm{R}=-1$ and 0.3 . The loading conditions of these two specimens are also listed in Tab. 2.

Fig. 9 illustrates the microstructural features of sample A2, for which the sampling location (quadrate rabbet) is close to the outer boundary of the FiE (Fig. 9a). Fig. 9b presents the whole BFI of A2 and Fig. 9c illustrates the DFI of its local field, showing any position on the profile is original martensite microstructure. Fig. 9d shows the SAD pattern with slightly elongated spots, which is the result of localized plastic deformation. Fig. 9e shows isolated spot pattern indicating only one grain within the diffraction area of $200 \mathrm{~nm}$ in diameter. In brief, the result of Fig. 9 shows that the microstructure underneath the fracture surface in the FiE region does not undergo grain refinement, which may be related to insufficient pressing during cycling because of the relatively faster crack growth rate in the FiE region.

Fig. 10 illustrates the microstructural features of sample B5 (also cut from FiE region), similar to the results shown in Fig. 9. There is no evidence of microstructure refinement in spite of the high maximum stress $\left(\sigma_{\max }\right)$, suggesting that plastic deformation ahead of crack tip cannot cause the formation of nanograins.

\section{CONCLUSIONS}

$\mathrm{I}$ $\mathrm{n}$ this paper, a series of profile samples from two high-strength steels were prepared by FIB in CIR and FiE regions of failed specimens subjected to rotary bending and ultrasonic axial cycling up to VHCF regime with various stress ratios. Then such samples were observed by TEM with SAD detection. Based on the experimental investigations, the following conclusions were obtained: 

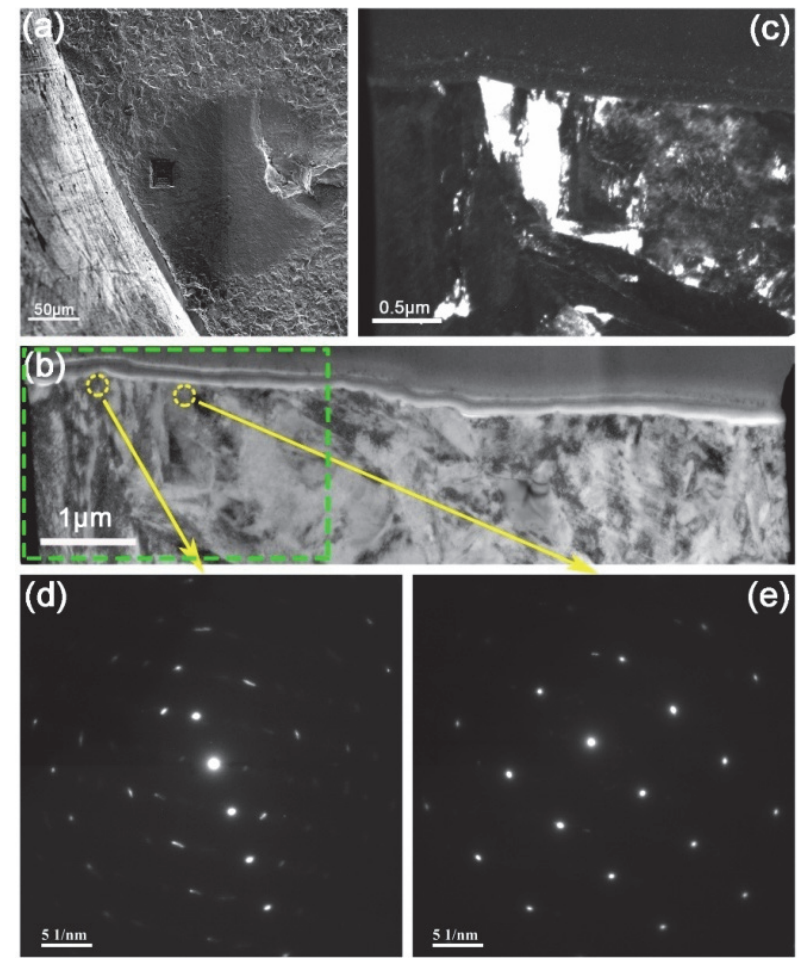

Figure 9: Microstructural feature of sample A2 $\left(\mathrm{RB}, R=-1, \sigma_{\mathrm{a}}=750 \mathrm{MPa}, N_{\mathrm{f}}=5.08 \times 10^{7}\right)$, (a) SEM image showing sampling location (quadrate rabbet); (b) BFI; (c) DFI of dashed green box in (b); (d,e) SAD patterns of the left and right dashed yellow circles in (b).
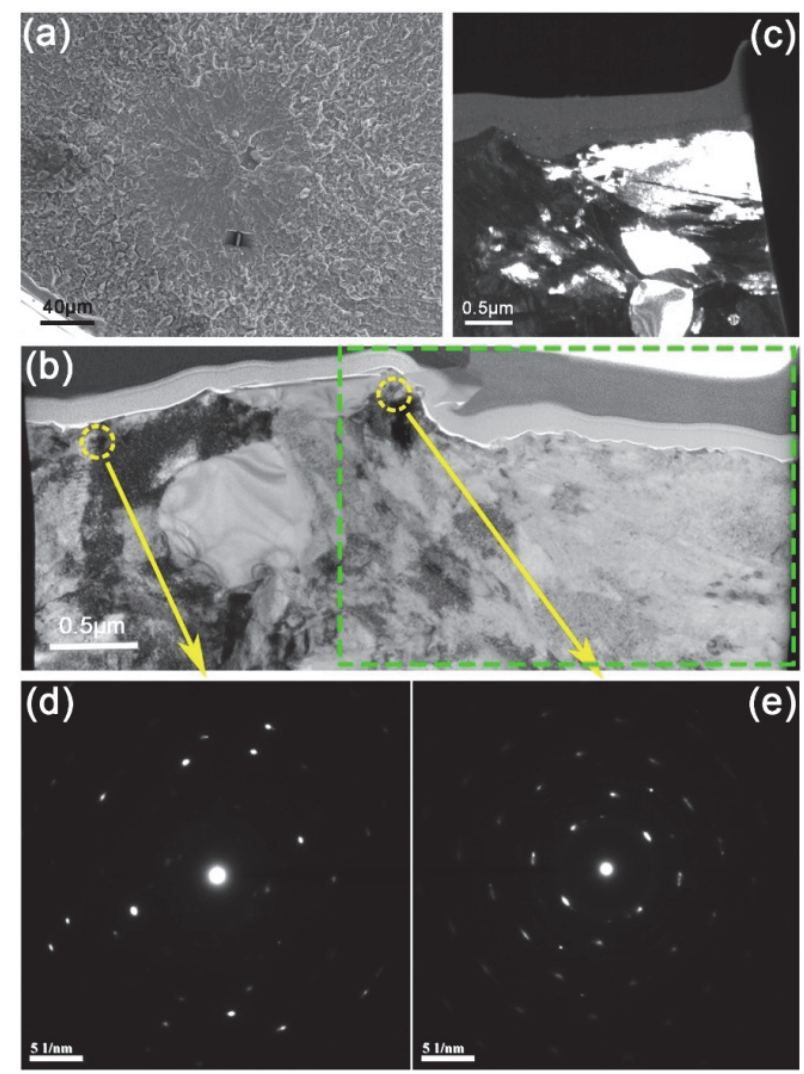

Figure 10: Microstructural feature of sample B5 (UL, $R=0.3, \sigma_{\mathrm{a}}=430 \mathrm{MPa}, N_{\mathrm{f}}=8.70 \times 10^{8}$ ), (a) SEM image showing sampling location (quadrate rabbet); (b) BFI; (c) DFI of dashed green box in (b); (d,e) SAD patterns of the left and right dashed circles in (b). 
(1) The NCP process dominates the formation of nanograin layer in CIR underneath FGA surface. Large compressive stress with sufficient pressing results in the formation of nanograins and consequently the nanograin layer.

(2) The plastic deformation at crack tip can only cause certain extent of deformation in microstructure of high-strength steels, but is insufficient to produce nanograins.

(3) There is no microstructure refinement in the FiE region no matter the sample was in the cases of negative or positive stress ratios, which may be due to the lack of crack surface contacting during cycling in the FiE region.

\section{ACKNOWLEDGEMENTS}

7 he financial supports from the National Natural Science Foundation of China (11572325) and from the Strategic Priority Research Program of the Chinese Academy of Sciences (XDB22040503, XDB22020201) are greatly appreciated.

\section{REFERENCES}

[1] Hong, Y. and Sun, C. (2017). The nature and the mechanism of crack initiation and early growth for very-high-cycle fatigue of metallic materials - An overview, Theoretical and Applied Fracture Mechanics, 92, pp. 331-350. DOI: 0.1016/j.tafmec.2017.05.002.

[2] Marines, I., Bin, X., Bathias, C. (2003). An understanding of very high cycle fatigue of metals, International Journal of Fatigue, 25(9-11), pp. 1101-1107. DOI: 0.1016/s0142-1123(03)00147-6.

[3] Mayer, H. (2016). Recent developments in ultrasonic fatigue, Fatigue and Fracture of Engineering Materials and Structures, 39(1), pp. 3-29. DOI: 10.1111/ffe.12365.

[4] Jeddi, D., Palin-Luc, T. (2018) A review about the effects of structural and operational factors on the gigacycle fatigue of steels. Fatigue and Fracture of Engineering Materials and Structures, 41(5), pp. 969-990. DOI: 10.1111/ffe.12779

[5] Krupp, U., Giertler, A., Koschella, K. (2017). Microscopic damage evolution during very-high-cycle fatigue (VHCF) of tempered martensitic steel, Fatigue and Fracture of Engineering Materials and Structures, 40(11), pp. 1731-1740. DOI: $10.1111 /$ ffe.12685.

[6] Hu, Y., Sun, C., Hong, Y. (2018) Crack growth rates and microstructure feature of initiation region for very - high cycle fatigue of a high-strength steel. Fatigue and Fracture of Engineering Materials and Structures, 41(8), 1717-1732. DOI: $10.1111 /$ ffe.12811

[7] Liu, X., Sun, C., Hong, Y. (2015). Effects of stress ratio on high-cycle and very-high-cycle fatigue behavior of a Ti6Al-4V alloy, Materials Science and Engineering, A: Structural Materials: Properties, Microstructure and Processing, 622, pp. 228-235. DOI: 10.1016/j.msea.2014.09.115.

[8] Pineau, A. and Forest, S. (2017). Effects of inclusions on the very high cycle fatigue behaviour of steels, Fatigue and Fracture of Engineering Materials and Structures, 40(11), pp. 1694-1707. DOI: 10.1111/ffe.12649.

[9] Shiozawa, K. and Lu, L. (2002). Very high-cycle fatigue behaviour of shot-peened high-carbon-chromium bearing steel, Fatigue and Fracture of Engineering Materials and Structures, 25, pp. 813-822.

[10] Hong, Y., Lei, Z., Sun, C., Zhao, A. (2014). Propensities of crack interior initiation and early growth for very-highcycle fatigue of high strength steels, International Journal of Fatigue, 58, pp. 144-151.

DOI: 10.1016/j.ijfatigue.2013.02.023.

[11] Lei, Z., Xie, J., Sun, C., Hong, Y. (2014). Effects of loading condition on very-high-cycle fatigue behaviour and dominant variable analysis, Science China-Physics Mechanics and Astronomy, 57(1), pp. 74-82. DOI: $10.1007 / \mathrm{s} 11433-013-5332-x$.

[12] Shyam, A., Blau, P., Jordan, T., Yang, N. (2014). Effect of submillimeter size holes on the fatigue limit of a high strength tool steel, Fatigue and Fracture of Engineering Materials and Structures, 37(4), pp. 368-379. DOI: $10.1111 /$ ffe.12119.

[13] Stanzl-Tschegg, S.E. (2017). Fracture mechanical characterization of the initiation and growth of interior fatigue cracks, Fatigue and Fracture of Engineering Materials and Structures, 40(11), pp. 1741-1751. DOI: 10.1111/ffe.12622.

[14] Marines-Garcia, I., Paris, P. C., Tada, H., Bathias, C. (2007). Fatigue crack growth from small to long cracks in veryhigh-cycle fatigue with surface and internal "fish-eye" failures for ferrite-perlitic low carbon steel SAE 8620, Materials Science and Engineering a-Structural Materials Properties Microstructure and Processing, 468, pp. 120-128.

DOI: $10.1016 /$ j.msea.2006.08.131. 
[15] Grad, P., Reuscher, B., Brodyanski, A., Kopnarski, M., Kerscher, E. (2012). Mechanism of fatigue crack initiation and propagation in the very high cycle fatigue regime of high-strength steels, Scripta Materialia, 67(10), pp. 838-841.

DOI: $10.1016 /$ j.scriptamat.2012.07.049.

[16] Hong, Y., Liu, X., Lei, Z., Sun, C. (2016). The formation mechanism of characteristic region at crack initiation for very-high-cycle fatigue of high-strength steels, International Journal of Fatigue, 89, pp. 108-118. DOI: $10.1016 /$ j.ijfatigue.2015.11.029.

[17] Murakami, Y., Nomoto, T., Ueda, T. (1999). Factors influencing the mechanism of superlong fatigue failure in steels, Fatigue and Fracture of Engineering Materials and Structures, 22, pp. 581-590.

[18] Sakai, T., Harada, H., Oguma, N. (2006). Crack initiation mechanism of bearing steel in very high cycle fatigue, Proceedings of ECF-16, CD-ROM.

[19] Shiozawa, K., Morii, Y., Nishino, S., Lu L. (2006). Subsurface crack initiation and propagation mechanism in highstrength steel in a very high cycle fatigue regime, International Journal of Fatigue, 28(11), pp. 1521-1532. DOI: $10.1016 /$ j.ijfatigue.2005.08.015.

[20] Shanyavskiy, A.A. (2013). Very-High-Cycle-Fatigue of in-service air-engine blades, compressor and turbine, Science China Physics, Mechanics and Astronomy, 57(1), pp. 19-29. DOI: 10.1007/s11433-013-5364-2.

[21] Gerbe, S., Krupp, U., Michels, W. (2019). Influence of secondary dendrite arm spacing (SDAS) on the fatigue properties of different conventional automotive aluminum cast alloys, Frattura ed Integrità Strutturale, 48, pp. 105115. DOI: $10.3221 /$ IGF-ESIS.48.13

[22] Sakai, T. (2009). Review and prospects for current studies on very high cycle fatigue of metallic materials for machine structural use, Journal of Solid Mechanics and Materials Engineering, 3, pp. 425-439. DOI: 10.1299/jmmp.3.425.

[23] Spriestersbach, D. and Kerscher, E. (2018). The role of local plasticity during very high cycle fatigue crack initiation in high-strength steels, International Journal of Fatigue, 111, pp. 93-100. DOI: 10.1016/j.ijfatigue.2018.02.008.

[24] Chai, G., Forsman, T., Gustavsson, F. (2016). Microscopic and nanoscopic study on subsurface damage and fatigue crack initiation during very high cycle fatigue, International Journal of Fatigue, 83, pp. 288-292.

DOI: 10.1016/j.ijfatigue.2015.10.024.

[25] Chai, G., Forsman, T., Gustavsson, F., Wang, C. (2015). Formation of fine grained area in martensitic steel during very high cycle fatigue, Fatigue and Fracture of Engineering Materials and Structures, 38(11), pp. 1315-1323. DOI: $10.1111 /$ ffe.12345.

[26] Jiang, Q., Sun, C., Liu, X., Hong, Y. (2016). Very-high-cycle fatigue behavior of a structural steel with and without induced surface defects, International Journal of Fatigue, 93, pp. 352-362. DOI:10.1016/j.ijfatigue.2016.05.032.

[27] Pan, X., Su, H., Sun, C., Hong, Y. (2018). The behavior of crack initiation and early growth in high-cycle and veryhigh-cycle fatigue regimes for a titanium alloy, International Journal of Fatigue, 115, pp. 67-78.

DOI: $10.1016 /$ j.ijfatigue.2018.03.021.

[28] Su, H., Liu, X., Sun, C., Hong, Y. (2017). Nanograin layer formation at crack initiation region for very-high-cycle fatigue of a Ti-6Al-4V alloy, Fatigue and Fracture of Engineering Materials and Structures, 40(6), pp. 979-993. DOI: $10.1111 /$ ffe. 12562 .

[29] Ritz, F., Stäcker, C., Beck, T., Sander, M. (2018). FGA formation mechanism for X10CrNiMoV12-2-2 and 34CrNiMo6 for constant and variable amplitude tests under the influence of applied mean loads, Fatigue and Fracture of Engineering Materials and Structures, 41(7), pp. 1576-1587. DOI: 10.1111/ffe.12797.

[30] Williams, D.B., Carter, C.B. (2009), Transmission Electron Microscopy: A Textbook for Materials Science, Second edition, Springer.

[31] Murakami, Y., Kodama, S., Konuma, S. (1989). Quantitative evaluation of effects of non-metallicinclusions on fatigue strength of high strength steels. I: Basic fatigue mechanism and evaluation of correlation between the fatigue fracture stress, International Journal of Fatigue, 11(5), pp. 291-298.

[32] Zhao, A., Xie, J., Sun, C., Lei, Z., Hong, Y. (2011). Prediction of threshold value for FGA formation, Materials Science and Engineering, A: Structural Materials: Properties, Microstructure and Processing, 528(22-23), pp. 68726877. DOI: $10.1016 /$ j.msea.2011.05.070. 